\title{
PROGRAMA MULHERES MIL: A OPORTUNIDADE DE RESGATAR UM SONHO
}

\section{RESUMO}

Este relato de experiência da execução do Programa Mulheres Mil tem como objetivo analisar a implantação do Programa, inserido no ano de 2012, no IFRN, Campus São Gonçalo do Amarante, tendo como público-alvo mulheres pertencentes às comunidades que apresentam vulnerabilidade, no município de São Gonçalo do Amarante/RN. Para isso, descrever-se-á a forma como o programa foi organizado na Instituição, as buscas ativas nas comunidades, as principais ações, a importância com as parcerias e os resultados obtidos. Como principais resultados, percebeu-se que o Instituto passou a identificar as necessidades sociais do munícipio, e, entre as alunas, observou-se o resgate de um sonho adormecido.

Palavras-chave: Programa Mulheres Mil. Inclusão social. Gênero.

\section{INTRODUÇÃO}

O Programa Mulheres Mil, iniciado em 2005 no Brasil, é decorrente da cooperação internacional Brasil-Canadá. Contou com a ousadia e coragem do IFRN, na época Centro Federal de Educação Profissional e Tecnológica (Cefet), com o lançamento de um projeto de extensão que ofereceu capacitação para camareiras. O resultado foi tão impactante no Canadá, que a Associação dos Colleges Comunitários Canadenses e a Secretaria de Educação Profissional e Tecnológica (Setec), no Brasil, resolveram construir um projeto e ampliar para os demais estados brasileiros nascendo então o Programa Mulheres Mil. O Programa Mulheres Mil - Educação, Cidadania e Desenvolvimento Sustentável, foi instituído pela Portaria no 1.015, de 21 de julho de 2011, está inserido no Plano Brasil sem Miséria, sendo atualmente executado pelos Institutos Federais no âmbito do Programa de Acesso ao Ensino Técnico e Emprego (Pronatec), integrante das políticas públicas do Governo Federal.

Adaptado à realidade do município de São Gonçalo do Amarante, onde o programa foi instituído para oferecer formação profissional e tecnológica às mulheres em situação de vulnerabilidade social, melhorando as condições de vida em que elas e suas famílias vivem. o programa prevê a sistematização de um plano educacional que possibilite a elevação da escolaridade e a inclusão das mulheres no

1 Núcleo de Estudo e Pesquisa em Educação, Gênero e Diversidade - NEGêDI, Campus São Gonçalo - Instituto Federal do Rio Grande do Norte, IFRN. E-mail: ideize.medeiros@ifrn.edu.br. 
mercado de trabalho por meio da oferta de cursos de Formação Inicial e Continuada (FIC) ligados ao Programa Mulheres Mil, fundamentados na metodologia do sistema de acesso, permanência e êxito.

Embora o Programa Mulheres Mil tenha uma metodologia própria, a Instituição construiu uma forma específica, vinculada à realidade regional e ao público-alvo. Os cursos ofertados no campus São Gonçalo do Amarante foram de Zeladoria, com carga horária de 164 horas; Auxiliar em Administração e Introdução à Informática, ambos com 160 horas, destinados às mulheres das comunidades do entorno do campus que, por muito tempo, tiveram seus sonhos adormecidos por falta de oportunidades. Além de estimular o aumento da escolaridade, esses cursos trabalharam aspectos sociais como os direitos e saúde da mulher, ética e cidadania, qualidade de vida e relações humanas no trabalho e na família.

Nesse sentido, o objetivo deste artigo resumido é relatar brevemente a experiência da implantação do Programa Mulheres Mil no Campus São Gonçalo do Amarante, destacando a importância desse Programa para a promoção da igualdade de gênero na região em que o Campus está instalado.

\section{DESENVOLVIMENTO DO PROJETO}

O Instituto Federal do Rio Grande do Norte - Campus São Gonçalo do Amarante decidiu fazer parte de um programa que vem promovendo a inovação na cultura institucional a partir do momento em que os cursos ofertados contemplam as características de cada comunidade do município, proporcionando às mulheres oportunidade de acesso à educação e ao mundo do trabalho, promovendo, assim, o crescimento humano, melhoria das condições de vida sociocultural e econômica e promoção da cidadania.

No momento da implantação do programa noIFRN-CampusSão Gonçalo do Amarante, noano de 2012, buscou-se, primeiramente, apresentar e discutir o guia metodológico do sistema de acesso, permanência e êxito aos docentes e técnicosadministrativos que iriam participar do programa (Figura 1). Nesse momento, foi realizada uma oficina organizada pela equipe pedagógica e pela coordenação do programa no âmbito do Campus. Dividiu-se o guia metodológico para 3 (três) grupos de docentes, que iriam ministrar aulas no programa, e cada grupo ficou com um tema.
Os temas discutidos foram: 1. A implementação do Projeto Mulheres Mil, conceito e o plano de comunicação; 2. Módulo permanência e êxito; 3. Serviço de assistência e apoio à educanda. Esse guia foi um instrumento facilitador no processo de implantação, nas ações, no acolhimento e na estruturação do desenvolvimento e qualificação.

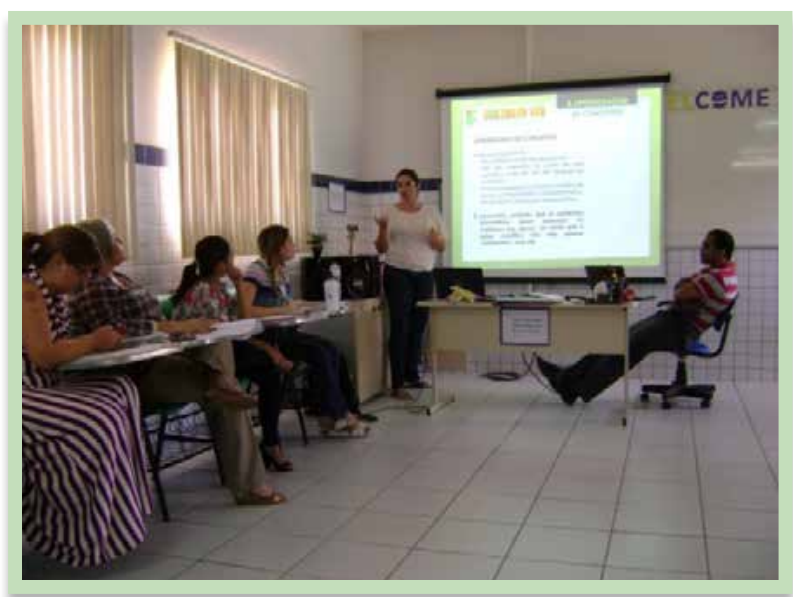

Figura 1: Apresentação e discussão do guia metodológico do sistema de acesso, permanência e êxito

No segundo momento, reuniram-se a Direção-Geral do Campus, a representante da equipe pedagógica e os parceiros da gestão do município para decidirem quais as comunidades que seriam atendidas no programa (Figura 2).

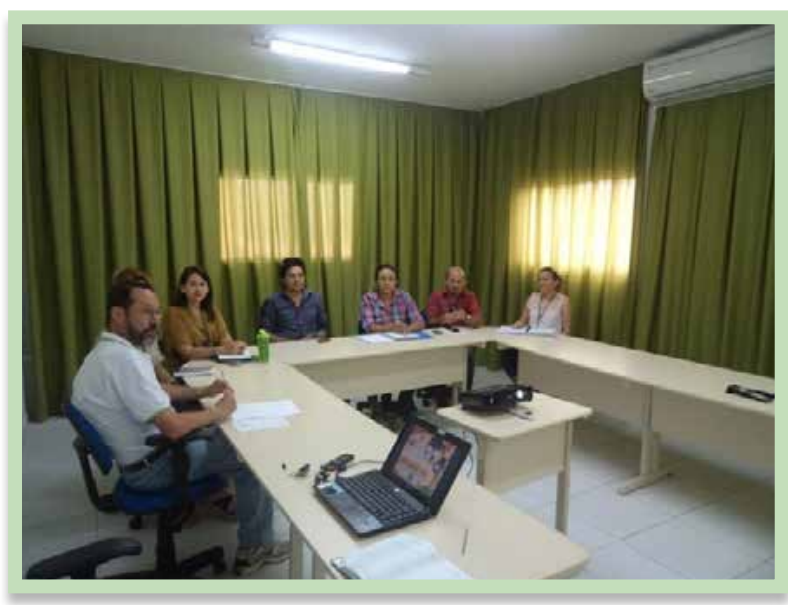

Figura 2: Reunião para definir quais comunidades seriam atendidas pelo Programa

Foram selecionadas previamente 6 (seis) comunidades, porém somente 3 (três) foram acolhidas para o momento de implantação. Essas comunidades escolhidas para este primeiro momento foram: Padre João Maria, Coqueiros e Sítio Jacaraú. Para o ano seguinte ficaram Serrinha, Guandupa e Barreiros. Depois da 
escolha, agendamos as visitas para apresentação do programa nas 3 (três) primeiras comunidades. Realizamos a primeira reunião na comunidade Padre João Maria, na sede do CRAS - Centro de Referência de Assistência Social. A segunda foi realizada com mais 2 (duas) comunidades: Coqueiros e Sítio Jacaraú, na escola municipal de Coqueiros.

Foram ofertadas 100 vagas, distribuídas em 4 (quatro) turmas, sendo 2 (duas) para cada turno. $\mathrm{Na}$ amostra das 100 mulheres selecionadas que ingressaram nessas turmas, 55 delas têm ensino fundamental incompleto; 7, ensino fundamental completo; 15, ensino médio incompleto; e 5, ensino médio completo. Elas recebem entre meio e um salário mínimo, e 78\% têm filhos. As atividades da implantação do programa foram iniciadas com uma aula inaugural no Teatro Municipal Prefeito Poti Cavalcanti, no dia 26 de novembro de 2012, com a presença do Reitor do IFRN, do DiretorGeral do Campus e do prefeito do município e outras autoridades. Em 5 de dezembro de 2012, nas dependências do Instituto, começaram as aulas oficialmente dos cursos e foram concluídas em 25 de abril de 2013. O percentual de evasão foi de $6 \%$, por motivo de trabalho e mudança de endereço para outro município.

O Programa Mulheres Mil vem sendo um instrumento transformador na vida de muitas mulheres atendidas, incentivando o aumento da escolaridade e elevando a sua autoestima. Tudo isso pode ser confirmado no depoimento da aluna Maria Lúcia da Silva, do curso de Zeladoria, no encerramento das aulas:

Falar do curso Mulheres Mil pra mim é falar de uma conquista de um sonho que estava adormecido. Mas, a partir do dia em que entrei nesta instituição, comecei a acreditar que sou capaz de realizar meus desejos. Faz 13 anos que parei de estudar, então este curso para mim foi uma oportunidade para sair em busca dos meus sonhos. E agora vou dar início a uma nova etapa após Mulheres Mil, e a primeira coisa é voltar a estudar, para poder ter mais conhecimento e assim ter como ajudar a minha comunidade, já que faço trabalho comunitário na Igreja Católica.

O projeto de extensão Práticas Corporais: Mulheres Mil em Movimento, idealizado durante a oficina de qualidade de vida pela professora de educação física Iracyara Maria Assunção de Souza e pelos bolsistas Murilo Éden da Silva e Pedro
Rangel Barbosa dos Santos, teve uma boa aceitação pelas mulheres, e algumas delas solicitaram a continuação desse projeto (Figura 3). A aluna Francisca de Assis, do curso de Zeladoria, assim nos falou: "achei ótima as palestras de qualidade de vida, aprendi muito, e os alongamentos, o banho de piscina me deixaram relaxada, dormi muito bem à noite depois das atividades".

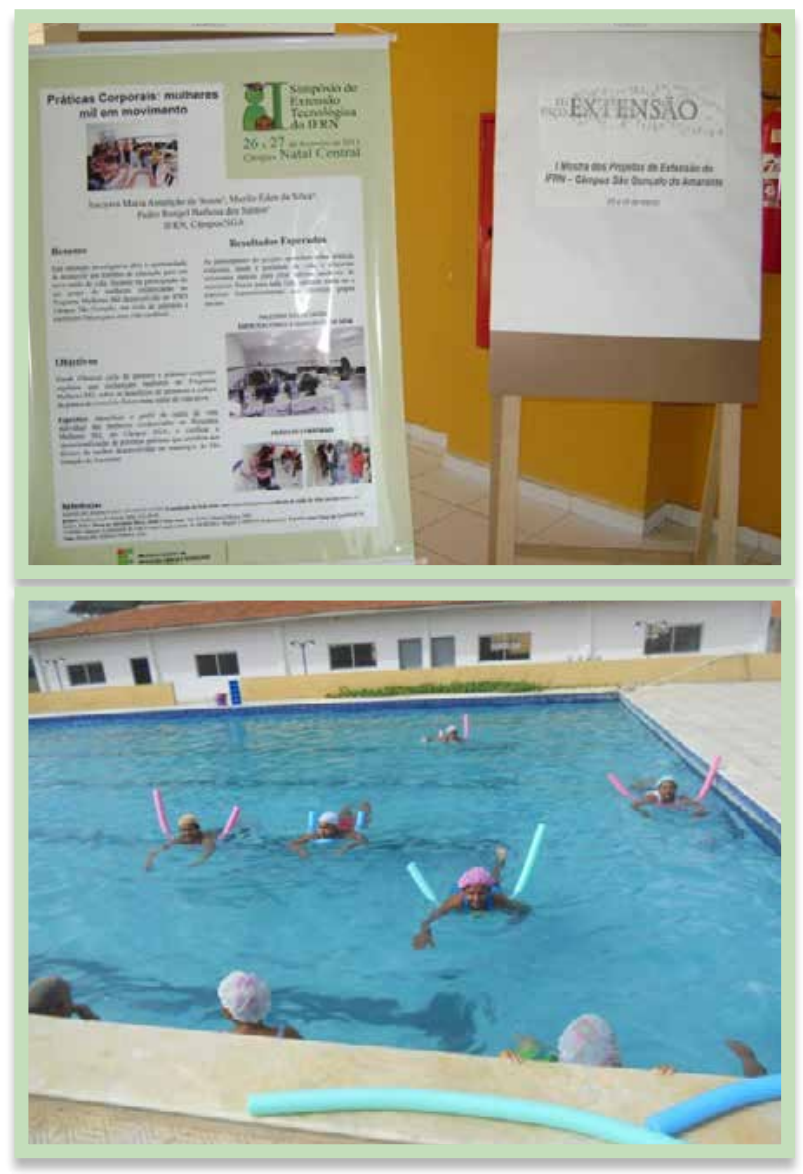

Figura 3:Projeto de extensão Práticas Corporais: Mulheres Mil em Movimento

Dando continuidade aos projetos, foi ofertado para as alunas matriculadas no curso de Zeladoria um curso extracurricular de olericultura básica e orgânica (Figura 4), ministrado pelo Serviço Nacional de Aprendizagem Rural (SENAR/ RN), um dos nossos colaboradores. Nesse curso as alunas aprenderam a construir canteiros para produção de folhagens e a produzir húmus orgânicos. As que já cultivavam horta em suas casas, auxiliaram as companheiras e fizeram a sua reciclagem e, ao término do curso, receberam o certificado. 


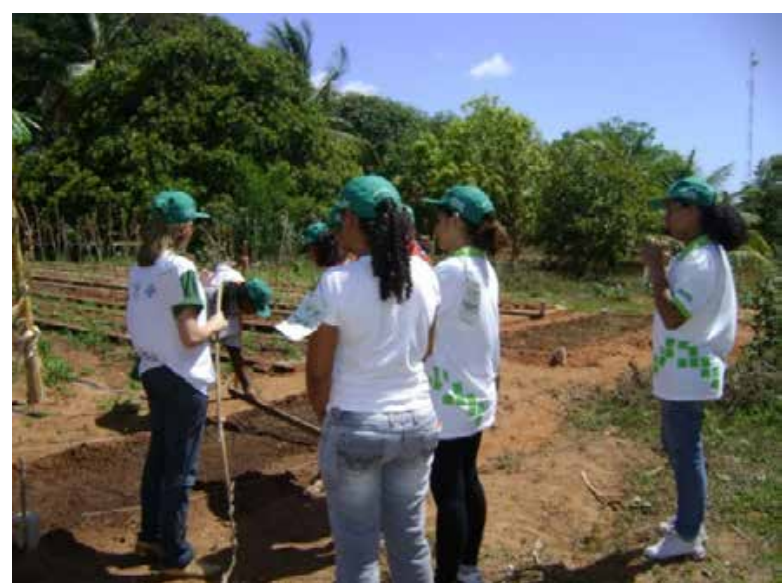

Figura 4: Aula do curso extracurricular de olericultura básica e orgânica

Ao longo do curso houve visitas técnicas referentes aos cursos, as alunas participaram de algumas ações comemorativas, como do Dia Internacional da Mulher e o Outubro Rosa, dentro da disciplina Cidadania e Direito da Mulher. $\mathrm{Na}$ programação do calendário acadêmico, tiveram uma participação surpreendente, ficando em 3o lugar na gincana educativa da Semadec Semana de Arte, Cultura e Desporto. Além disso, participaram de ação social contra a dengue promovida pelo município em parceria com IFRN.

\section{CONSIDERAÇÕES FINAIS}

O Programa Mulheres Mil vem sendo um instrumento transformador na vida de muitas mulheres atendidas, incentivando o aumento da escolaridade, promovendo uma mudança relevante nas condições de vulnerabilidade social, cultural e elevando a sua autoestima, além de influenciar pessoal e profissionalmente a equipe na construção do plano de trabalho no Campus.

Encontramos nesse programa uma oportunidade de favorecer a troca de experiências, o compartilhamento das dificuldades e das soluções encontradas e a união de ideias e de ações de modo a sanar nossas dificuldades e nortear nossas ações, sempre pretendendo alcançar a excelência.

\section{REFERÊNCIAS}

BRASIL. Lei no 9.394 de 20 de dezembro de 1996. Estabelece as diretrizes e bases da educação nacional.

- Ministério da Educação. Portaria n. 1.1015, de 21 de julho de 2011. Institui o
Programa Nacional Mulheres MIL - Educação, Cidadania e Desenvolvimento.

Guia Metodológico do Sistema de Acesso. Permanência e êxito. Disponível em: <mulheresmil.mec.gov.br>. Acesso em: 06 ago. 2014.

PEREIRA, Eliane Auxiliadora. Relato de experiência da execução do curso FIC Mulheres Mil no município de Porto Velho, Rondônia. InfoEXT - Campus Porto Velho Calama, Porto Velho/RO, ano I, n. 1, out. 2013. 